\title{
Monoclonal Antibodies Directed against Surface-associated Polypeptides of Treponema pallidum Define a Biologically Active Antigen
}

\author{
By M. J. BAILEY,*A. COCKAYNE AND C. W. PENN \\ Department of Microbiology, University of Birmingham, Birmingham B15 2TT, UK
}

(Received 11 November 1986; revised 7 March 1987)

Murine monoclonal antibodies (Mabs) were raised against two outer-membrane-associated polypeptides of Treponema pallidum ( 47 and $44 \mathrm{kDa}$ ). Three Mabs against each polypeptide were investigated further and only those directed against the $44 \mathrm{kDa}$ polypeptide were demonstrated to have immobilizing activity. The specificity of the Mabs for $T$. pallidum was determined by Western blotting procedures and the surface association of the antigens was inferred by immunogold electron microscopy. The clear distinction between these two polypeptides in their biological activity could help to explain the pathobiology of syphilis infections as the $47 \mathrm{kDa}$ antigen has been shown to be associated with the outer membrane of this organism. Inactivity of such a surface-located protein in antibody-mediated anti-treponemal mechanisms could account for the observed ability of this organism to survive in the face of strong antibody responses in infection.

\section{INTRODUCTION}

Factors influencing propagation of the causative agent of syphilis (Treponema pallidum) in vitro have yet to be fully elucidated. In spite of the attempts made and the limited successes recorded (Fieldsteel et al., 1981, 1982; Norris, 1982) a simple reliable cultivation protocol has not been developed. In view of the limited numbers of treponemes available for analysis from infected animals, alternative approaches for the study of treponemal pathogenicity, immunodiagnosis and immunprophylaxis have to be pursued. These include the production of monoclonal antibodies (Mabs) and genetically cloned antigens. These techniques rely on the positive identification of constituent treponemal polypeptides and/or antigens, but without large quantities of bacteria little structural or functional information can be ascribed to any polypeptide isolated.

A number of immunodominant antigens have been identified in $T$. pallidum by analysis of the humoral response in infected animals or humans (Baseman \& Hayes, 1980; Alderete \& Baseman, 1981; Pedersen et al., 1981; Hanff et al., 1982; Lukehart et al., 1982, 1986; Penn \& Rhodes, 1982; Hanff et al., 1983a, b; Moskophidis \& Muller, 1984; Baker-Zander et al., 1985). Through the labelling of $T$. pallidum with ${ }^{125} \mathrm{I}$, the surface location of a number of polypeptides has been inferred (Alderete \& Baseman, 1980; Norris \& Sell, 1984). However, few chemical or immunochemical data are available to identify the cellular location of such antigens or show whether any elicit neutralizing antibody. The interpretation of such findings must be cautious, especially because of the possibility that organisms may become damaged during preparation,

\footnotetext{
Abbreviations: 1D, one-dimensional; 2D, two-dimensional; FCS, foetal calf serum; Mab, monoclonal antibody; NCM, nitrocellulose membrane(s); NRS, normal rabbit sera; PAT; PBS containing $0.1 \%$ BSA and $0.1 \%$ Tween; MvTp, hyperimmune mouse anti-T. pallidum sera; p.i., post infection; RIP, radioimmunoprecipitation; RSS, rabbit syphilitic sera; hRSS, hyperimmune rabbit syphilitic sera; cRSS, convalescent rabbit syphilitic sera; TPI assay, $T$. pallidum immobilization assay.
} 
as Penn et al. (1985) were unable to label any $T$. pallidum polypeptides by the iodination of freshly extracted unwashed treponemes, suggesting the absence of exposed proteins at the surface of the intact organism.

A number of groups have reported the generation of Mabs against an immunodominant polypeptide with a molecular mass of approximately $47 \mathrm{kDa}$ (Robertson et al., 1982; Van Embden et al., 1983; Thornburg \& Baseman, 1983; Thornburg et al., 1985; Lukehart et al., 1985), which could possibly be the Triton X-100-extractable membrane-associated polypeptide described previously by us (Penn et al., 1985). In support of this, Marchitto et al. (1984) showed that two Mabs with specificity for a $47 \mathrm{kDa}$ polypeptide (11E3 and 13C6) could be demonstrated at the surface of organisms by immunogold staining, and that by immunoblotting a similar protein could be identified in $T$. pertenue and the T. pallidum subspecies endemicum (Bosnia A). In an extension of this work Jones et al. (1984) clearly demonstrated that one of these Mabs, $11 \mathrm{E} 3$, had biological activity and was able to immobilize $T$. pallidum in vitro, to neutralize $T$. pallidum in the in vitro-in vivo test of Bishop \& Miller (1976), and also to react with the polypeptide in native or partially denatured states, as determined by radioimmunoprecipitation (RIP) and immunoblotting respectively. They did not however comment on the biological activity of their other Mab, 13C6. We consider that this is important as the distribution of polypeptides around $47 \mathrm{kDa}$ is highly complex and by one-dimensional (1D) electrophoresis on non-gradient SDS-PAGE is poorly resolved, leading to some confusion of the true binding specificity of antibody when either immunoblotting or RIP techniques are used. Further to this, immunoblot profiles of sera from infected rabbits reveal that an early antibody response to the $47 \mathrm{kDa}$ antigen is elicited despite the lack of clearance of the organism from lesions.

In this paper we describe the generation of a bank of Mabs to two immunodominant surfaceassociated polypeptides of 44 and $47 \mathrm{kDa}$, and demonstrate their differential ability to immobilize $T$. pallidum in vitro, and react specifically with pathogenic treponemes. These results support the view that the $44 \mathrm{kDa}$ antigen has immunomodulating activity and that the $47 \mathrm{kDa}$ antigen does not elicit immobilizing antibody.

\section{METHODS}

Bacterial strains and antigens. T. pallidum (Nichols) isolate (Penn, 1981) was routinely propagated in the testes of Dutch or Californian rabbits (Hyline, Warrington, UK), and harvested as previously described (Penn \& Rhodes, 1982; Penn, 1983). After extraction of $T$. pallidum from the testes the suspension was centrifuged at $500 \mathrm{~g}$ to deposit gross host cell debris and the supernatant was retained. Before use as a source of antigen, $T$. pallidum cells were killed by incubation at $4{ }^{\circ} \mathrm{C}$ for $>18 \mathrm{~h}$ in the presence of $0.1 \%(\mathrm{w} / \mathrm{v}) \mathrm{NaN}_{3}$; they were used within $72 \mathrm{~h} . T$. phagedenis (biotype Reiterii) was obtained from the Venereal Disease Reference Laboratory, London Hospital, and grown in Spirolate broth (Becton Dickinson) supplemented with $10 \%(\mathrm{v} / \mathrm{v})$ newborn calf serum (Flow) at $37^{\circ} \mathrm{C}$ for 48-72 h (Penn \& Rhodes, 1982). T. hyodysenteriae, the causative agent of swine dysentery, was donated as a frozen pellet of whole cells (strain P18A) by Dr Ruth Lemcke, Institute for Research on Animal Diseases, Compton, Newbury, Berks., UK.

All treponemal strains were pelleted at $11600 \mathrm{~g}$ and washed three times in phosphate-buffered saline $\mathrm{pH} 7.2$ (PBS: $7.2 \mathrm{~mm}-\mathrm{Na}_{2} \mathrm{HPO}_{4}, 2.8 \mathrm{mM}-\mathrm{NaH}_{2} \mathrm{PO}_{4}, 0.15 \mathrm{M}-\mathrm{NaCl}$ ) prior to use.

Outer membrane preparation. The Triton-soluble membrane fraction was prepared according to the method of Penn et al. (1985).

Ultrasonic disruption of T. pallidum. PBS-washed cells were resuspended in PBS to a final concentration of $5 \times$ $10^{9} \mathrm{ml}^{-1}$ and subjected to ultrasound from a $3 \mathrm{~mm}$ probe (Rapidis 180, Ultrasonics, Shipley, Yorks., UK) for a total of $3 \mathrm{~min}(12 \times 15 \mathrm{~s}$ bursts, $50 \mathrm{kHz})$ at $0^{\circ} \mathrm{C}$.

Uninfected rabbit tissue. Testicular material was extracted from healthy rabbits according to the protocol followed for $T$. pallidum isolation, except that the material sedimented by centrifugation at $500 \mathrm{~g}$ was collected, resuspended in PBS to an equivalent concentration of one extracted testis $\mathrm{ml}^{-1}$, ultrasonically disintegrated and stored at $-20^{\circ} \mathrm{C}$.

Antisera. Hyperimmune rabbit syphilitic sera (hRSS) were prepared in four rabbits (sera were pooled) which had been infected intratesticularly with $T$. pallidum $2-3$ months previously. These animals were immunized on three occasions thereafter at monthly intervals by the subcutaneous injection of a total of $1 \times 10^{9}$ azide-killed treponemes in Freund's incomplete adjuvant at four sites and boosted, $10 \mathrm{~d}$ before collection of serum, by the intravenous injection of $1 \times 10^{9}$ sonicated organisms. Rabbit syphilitic sera (RSS) were taken from the marginal ear vein of rabbits infected intratesticularly with $5 \times 10^{7}$ organisms per testis and bled at regular intervals 
thereafter. Convalescent rabbit syphilitic sera (cRSS) were collected from rabbits 6 months p.i. The sera collected were pooled and stored in small volumes at $-20^{\circ} \mathrm{C}$. All sera used in this study were thawed only once.

Immunization of mice. Female Balb/c mice (6-10 weeks old) were immunized with two different antigen preparations. To enhance the generation of antibody to surface components, individual mice were injected initially (day 0 ) with either live treponemes or azide-killed whole bacteria in Freund's complete adjuvant. A total of $1 \times 10^{8}$ cells in Freund's incomplete adjuvant were injected intraperitoneally 14,28 and $56 \mathrm{~d}$ later followed by the intravenous and intraperitoneal injection of the same dose of ultrasonically disrupted cells on day $63,4 \mathrm{~d}$ before fusion. Anti-T. pallidum sera (MvTp) were collected from spleen donors by cardiac puncture and used as control in the screening assays. Before boosting for fusions, serum samples were taken by tail snipping (Healing, 1978) and tested for the presence of desired antibody by Western blotting.

Hybridomas. The myeloma cell line NS-1 (Balb/c-MOPC 21 NS1/1) (Kholer \& Milstein, 1975) was originally obtained from Flow Laboratories. Cells were maintained in RPMI 1640 (Gibco) supplemented with $10 \%$ ( $/ \mathrm{v}$ ) FCS (BRL) and $100 \mathrm{U}$ penicillin/streptomycin $\mathrm{ml}^{-1}$, and grown at $37^{\circ} \mathrm{C}$ in $6 \%(\mathrm{v} / \mathrm{v}) \mathrm{CO}_{2}$. Fusions were performed at a $1: 4$ ratio of myeloma cells to splenocytes in the presence of $50 \%(\mathrm{w} / \mathrm{v})$ polyethylene glycol 1450 using standard procedures. Donor splenocytes were derived from mice immunized as described above.

Detection of antibody-producing hybridomas. Fourteen days after fusion the culture supernatants were screened for the presence of $T$. pallidum-specific antibody by ELISA. Sonicated $T$. pallidum cells were diluted in carbonate/bicarbonate buffer $\mathrm{pH} 9.6$ (Voller et al., 1979) to $2 \times 10^{7} \mathrm{ml}^{-1}$, and $100 \mu \mathrm{l}$ added to each well of a Nunc type 1 EIA 96-well plate (Gibco). Antigen was allowed to adsorb to the solid phase overnight at $4{ }^{\circ} \mathrm{C}$, or alternatively the antigen was dried onto the plate by incubation at $45^{\circ} \mathrm{C}$ for $6 \mathrm{~h}$. After incubation with culture supernatant, antibody-reactive wells were identified with rabbit anti-mouse peroxidase conjugate using $o$ phenylenediamine as substrate. Identified hybidomas were then fed with $100 \mu \mathrm{HT}$ medium and further tested by ELISA for non-reactivity with uninfected rabbit testicular material and by strip immunoblotting. Hybridomas secreting the desired antibody were cloned out twice by limiting dilution. All data presented here were generated from tissue-culture-derived antibody. For in vitro immobilization assays antibody was concentrated by ammonium sulphate precipitation from cultures grown in the absence of antibiotics. Immunoglobulin class specificity was determined by double immunodiffusion, in $1 \%(\mathrm{w} / \mathrm{v})$ agarose in barbitone buffer $\mathrm{pH} 8 \cdot 2$, using anti-mouse subclass antisera supplied by Dr D. Catty, Department of Immunology, University of Birmingham, UK.

SDS-PAGE and immunoblotting. ID electrophoretic separation of antigens was achieved in $8-20 \%(\mathrm{w} / \mathrm{v})$ continuous gradient acrylamide gels, using the buffer systems of Laemmli (1971). PBS-washed treponemal cells in dissociating buffer $\left(2 \times 10^{7}\right.$ per $\left.20 \mu \mathrm{l}\right)$ were boiled for $5 \mathrm{~min}$ and run until the dye front was within $1 \mathrm{~cm}$ of the end of the gel. After electrophoresis, gels were either stained with PAGE Blue $83(\mathrm{BDH})$ or transferred to nitrocellulose membranes (BA85, 0.45 $\mu \mathrm{m}$, Schleicher \& Schuell) (NCM) using the Bio-Rad Trans-Blot apparatus at $100 \mathrm{~mA}$ $(15 \mathrm{~V})$ for $16 \mathrm{~h}$ essentially as described by Towbin et al. (1979). Immunological detection of treponemal antigens was accomplished after blocking non-specific binding to the NCM with $3 \%(w / v) ~ B S A, 0.1 \%(v / v)$ Tween 20 in PBS for 30 min at room temperature; culture supernatants or sera were diluted in PAT ( $0.1 \%$ BSA, $0.1 \%$ Tween 20 in PBS) as described in the legends and reacted with shaking for $2 \mathrm{~h}$. After five washes in PBS, horseradish peroxidase anti-species conjugates were added, diluted in PAT to $1 / 1500$ and reacted as above. Specific antibody binding was detected with 4-chloro-1-naphthol $[2 \%(\mathrm{w} / \mathrm{v})$ in methanol, $1.5 \mathrm{ml}$ in $50 \mathrm{ml} 50 \mathrm{mM}-\mathrm{Tris} / \mathrm{HCl} \mathrm{pH} 7.2$, $25 \mu 130 \% \mathrm{H}_{2} \mathrm{O}_{2}$ ]. In all cases $1 \mathrm{ml}$ solution was added per $3 \mathrm{~cm}^{2}$ of membrane.

Two-dimensional (2D) gel electrophoresis. Sample preparation and isoelectrofocusing were performed by a modification of the methods of O'Farrell (1975) and Norris \& Sell (1984). A total of $1.2 \times 10^{9} T$. pallidum cells were washed three times in PBS and resuspended in $125 \mu \mathrm{l} \mathrm{C} 2$ buffer [ $8 \%(\mathrm{v} / \mathrm{v})$ Nonidet P-40, $9 \cdot 2 \mathrm{M}$-urea, $5 \%(\mathrm{w} / \mathrm{v}) 2$ mercaptoethanol] and sonicated for $2 \mathrm{~min}$ at room temperature (Ultrasound waterbath). The sonicate was held on ice and any particulate matter removed by centrifugation at $11600 \mathrm{~g}$ for $3 \mathrm{~min}$ at $4{ }^{\circ} \mathrm{C}$. The supernatant solution $(28 \mu \mathrm{l})$ was loaded onto each $15 \mathrm{~cm} \times 1.5 \mathrm{~mm}$ isoelectrofocusing tube incorporating an ampholine $\mathrm{pH}$ gradient of $7-4$, established by prefocusing at $200 \mathrm{~V}$ for $1 \mathrm{~h}$ before sample application. The first dimension was run for $21.5 \mathrm{~h}$ at $700 \mathrm{~V}$, and the focused gel placed on top of an 8-18\% SDS-PAGE gradient slab-gel. The second dimension was run at $300 \mathrm{~V}, 4^{\circ} \mathrm{C}$ for $7.5 \mathrm{~h}$; included at the top edges of each second-dimension gel was a small plug of agarose containing boiled $T$. pallidum in Laemmli sample buffer. This produced a $1 \mathrm{D}$ display allowing the identification of the polypeptide spots in the 2D system. After the SDS-PAGE phase, gels were either fixed and stained with PAGE Blue 83 or silver (Oakley et al., 1980), or the separated polypeptides were transferred to NCM and reacted with Mab or sera as described above.

Immobilization studies. Immobilizing activity of sera and Mabs was tested by a modification of the T. pallidum immobilization (TPI) test described by Nelson \& Mayer (1949). Freshly harvested treponemes were centrifuged at $500 \mathrm{~g}$ to remove host cell debris and bacterial counts in these extracts were determined by phase-contrast light microscopy. The bacterial count was adjusted to $1 \times 10^{8} \mathrm{ml}^{-1}$ with extraction medium. Volumes $(100 \mu \mathrm{l})$ of the $T$. pallidum suspension were mixed with $20 \mu$ freshly collected normal rabbit sera (NRS) (source of complement) and either $10 \mu \mathrm{l} \mathrm{Mab}$ concentrate or $10 \mu \mathrm{l}$ RSS taken at known times p.i. The monoclonal antibody supernatants (10- 
$15 \mu \mathrm{g} \mathrm{ml}^{-1}$ ) were concentrated 40-fold by ammonium sulphate precipitation or protein-A column chromatography and adjusted to the same equivalent concentration before use; RSS were heat treated $\left(56^{\circ} \mathrm{C}, 30 \mathrm{~min}\right)$ before inclusion in the TPI test. Controls included NRS, heat-treated NRS, hRSS, cRSS and NS-1 supernatant. Incubation was conducted in an atmosphere of $\mathrm{N}_{2} / \mathrm{CO}_{2} / \mathrm{O}_{2}\left(92: 5: 3\right.$, by vol.) for $16 \mathrm{~h}$ at $35^{\circ} \mathrm{C}$ in Eppendorf $1.5 \mathrm{ml}$ polypropylene tubes in an anaerobic jar. The percentage of organisms remaining motile after incubation was determined by phase-contrast microscopy. Data represent reactivity $(+)$ or non-reactivity $(-)$ from at least six separate experiments.

Immunogold labelling. Viable or azide-killed treponemes were washed twice in PBS and resuspended in PBS to 1 $\times 10^{8} \mathrm{ml}^{-1}$. They were transferred to Formvar-coated copper grids, non-specific binding was blocked by $3 \%(\mathrm{w} / \mathrm{v})$ BSA in PBS and the treponemes were then reacted with antibody either directly or after fixation in $20 \%(\mathrm{v} / \mathrm{v})$ methanol for 2 min and washing in PBS. After washing away unbound antibody with PBS, grids were incubated with anti-species gold conjugate and negatively stained in $3 \%(\mathrm{w} / \mathrm{v})$ potassium phosphotungstate $\mathrm{pH} 7 \cdot 2$ in $\mathrm{H}_{2} \mathrm{O}$ for $30 \mathrm{~s}$ before viewing in a Philips 201 electron microscope as described previously (Cockayne et al., 1987). Treponemes recovered after incubation in the TPI test were also tested for their ability to bind the immunogold probe.

\section{RESULTS}

\section{Selection of antibody secreting hybridomas}

Primary screening of supernatants by ELISA for the presence of anti-T. pallidum antibody demonstrated that at least $15 \%$ of hybridoma wells contained reactive antibody. By Western blotting of ID gradient SDS-PAGE gels, two specificities of Mab were isolated, those that reacted with a $47 \mathrm{kDa}$ polypeptide and those that reacted with another polypeptide of $44 \mathrm{kDa}$ (Fig. 1). Three Mabs against each antigen were selected for further investigation, and their antibody class was determined by immunodiffusion (Table 1). None of these Mabs cross-reacted by standard immunoblotting with either $T$. phagedenis or $T$. hyodysenteriae (data not presented).

\section{$2 D$ characterization of treponemal antigens}

By silver staining 2D polyacrylamide gels (Fig. 2) a large number of diverse polypeptides were located. However, it was necessary to increase the voltage and time of isoelectric focusing to a total of $15000 \mathrm{~V} \mathrm{~h}$, from $7200 \mathrm{~V} \mathrm{~h}$ as described by Norris \& Sell (1984), in order to obtain clearly focused spots without streaking. This increased voltage input alters the apparent $\mathrm{pI}$ for the two polypeptides under investigation from pI 5.85, estimated after incomplete electrophoresis, to those values given below. At least eight polypeptides with similar molecular masses could be seen by silver staining in the immunodominant $47 \mathrm{kDa}$ region (Fig. $2 a$ ). The possibility that this diversity was attributable to degradation of one or two polypeptides, or an artefact of sample preparation, was examined by sequentially reacting a single $2 \mathrm{D}$ blot with each of the different Mabs generated in this study. Those Mabs recognizing the $44 \mathrm{kDa}$ antigen only reacted with the polypeptide of $44 \mathrm{kDa}$ in 1D gels, but if they were included for reaction with blots of $2 \mathrm{D}$ gels at elevated concentrations $(1 / 10)$ then a number of faint cross reactions could be observed (see spots on Fig. 2c); as the peptides located by this method all have the same pI (4.85) and react only with anti- $44 \mathrm{kDa}$ Mabs it is assumed that these additional bands represent breakdown cleavage products of the $44 \mathrm{kDa}$ antigen during sample preparation. The Mabs directed against the major Triton X-100-soluble outer-membrane polypeptide reacted with the $47 \mathrm{kDa}$ antigen, pI 4.9, and its precursor form (Fig. 2c, arrow). The specificity of the Mabs demonstrated here by 2D blotting clearly indicates that the faint to strong reactions seen with hRSS are due to a diverse range of polypeptides of differing antigenicity in this region which are not resolved by 1D systems, emphasizing that the identification of target antigens to which Mabs are raised solely by their molecular mass without isoelectric focusing data must be interpreted cautiously.

\section{Humoral response to $T$. pallidum antigens in the rabbit model}

Serum was taken at regular intervals after intratesticular infection of rabbits and reacted with Western blots of 1D gels. Antibody to a small number of treponemal antigens was detected within $10 \mathrm{~d}$ p.i. (Fig. 3). This antibody was predominantly of the IgM class at day 10 p.i. [as determined by a double antibody assay using goat anti-rabbit $\mu$-chain-specific immunoglobulin 


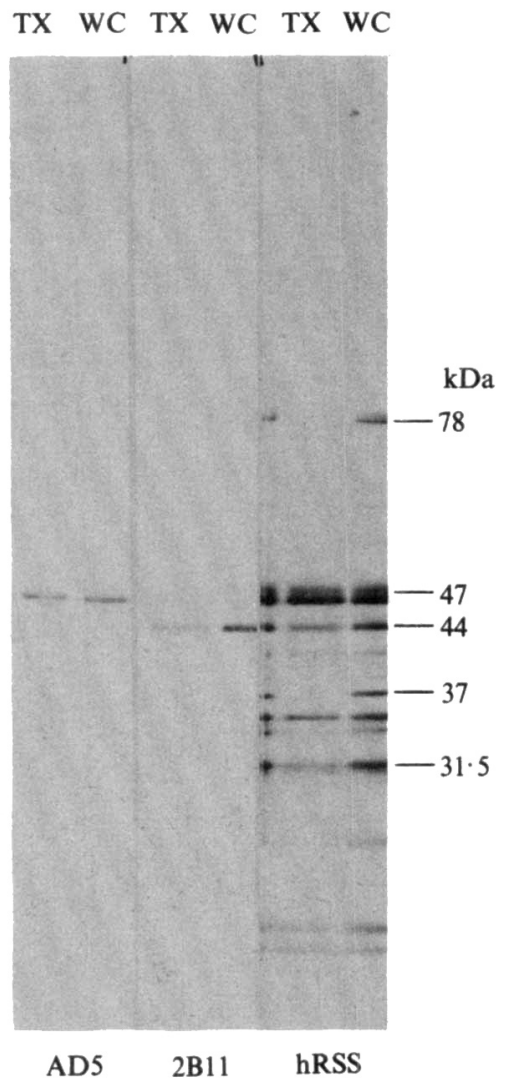

Fig. 1. Immunoblot analysis of the anti-47 kDa Mabs (i.e. AD5, 1/50), anti-44 kDa Mabs (i.e. 2BI1, 1/50) and hyperimmune rabbit syphilitic sera pool (hRSS, 1/500) against 8-20\% gradient SDS-PAGE polypeptide profiles of Triton X-100 extracts of $T$. pallidum (TX) and whole $T$. pallidum (WC).

Table 1. Antigenic specificity and immobilizing activity of anti-T. pallidum Mabs

\begin{tabular}{lccc}
\multicolumn{1}{c}{ Mab } & $\begin{array}{c}\text { Mol. mass* } \\
(\mathrm{kDa})\end{array}$ & $\begin{array}{c}\text { Isotype } \\
(\mathrm{IgG})\end{array}$ & TPI $\dagger$ \\
2B11 & 44 & 1 & + \\
2D7 & 44 & $?$ & + \\
AB4 & 44 & 1 & + \\
AD5 & 47 & 1 & - \\
AH9 & 47 & $2 \mathrm{a}$ & - \\
AD12 & 47 & $2 \mathrm{~b}$ & - \\
NS-1 supernatant & & & - \\
hRSS & & & + \\
cRSS & & & + \\
NRS & & & -
\end{tabular}

- Molecular mass of $T$. pallidum antigens recognized by the Mabs, as determined by Western blotting. $\dagger T$. pallidum immobilization test: + , reactive, - , non-reactive. 

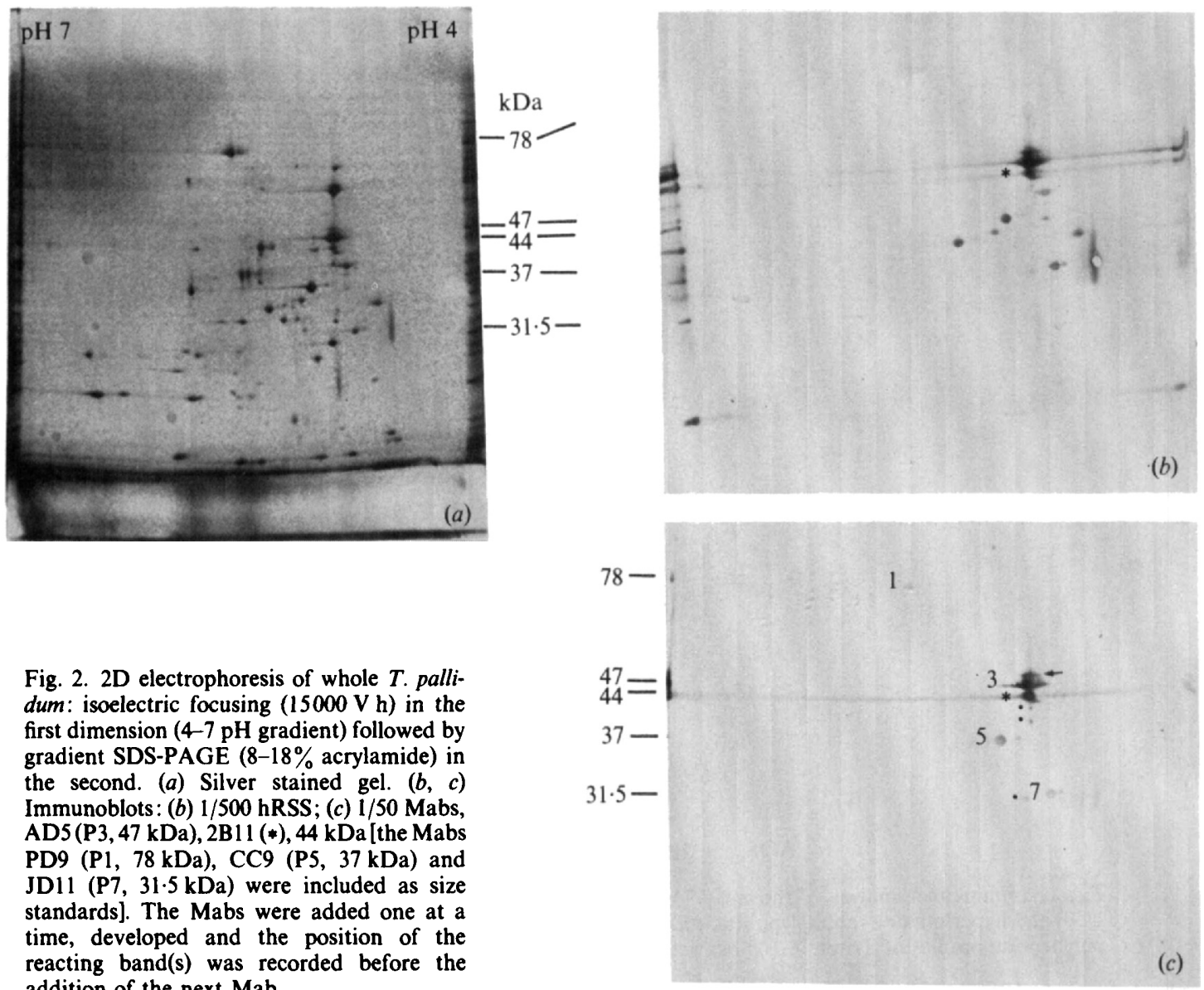

Fig. 2. 2D electrophoresis of whole $T$. pallidum: isoelectric focusing $(15000 \mathrm{~V} \mathrm{~h})$ in the first dimension $(4-7 \mathrm{pH}$ gradient) followed by gradient SDS-PAGE (8-18\% acrylamide) in the second. (a) Silver stained gel. $(b, c)$ Immunoblots: (b) 1/500 hRSS; (c) 1/50 Mabs, AD5 (P3, $47 \mathrm{kDa}), 2 \mathrm{~B} 11(*), 44 \mathrm{kDa}$ [the Mabs PD9 (P1, $78 \mathrm{kDa}), \mathrm{CC} 9$ (P5, $37 \mathrm{kDa})$ and JD11 (P7, 31.5 kDa) were included as size standards]. The Mabs were added one at a time, developed and the position of the reacting band(s) was recorded before the addition of the next Mab.

(Miles) on the immunoblots], and directed against two polypeptides of 47 and $37 \mathrm{kDa}$ (not shown). As the disease progressed a more diverse response was seen, predominantly of IgG. By days 14-17, when orchitis is on the decline and treponemes are being cleared from the lesion (Lukehart et al., 1986), a number of additional antigens were recognized, one of them the $44 \mathrm{kDa}$ polypeptide. Antibody titres to $T$. pallidum antigens increased with time p.i., as determined by indirect ELISA (Fig. 4b).

\section{Immobilization studies}

Results (Table 1) are expressed as reactive or non-reactive after incubation with the tested antibody. Complement-mediated killing was observed most strongly in hRSS and in cRSS. As the immune response progressed during experimental infection, TPI activity increased (Fig. $4 a$ ). The Mabs demonstrated significant differences in their ability to immobilize T. pallidum in vitro, with the anti- $44 \mathrm{kDa}$ Mabs active and the anti- $47 \mathrm{kDa}$ Mabs non-reactive. In control samples containing NS-1 supernatant, preimmune sera or samples lacking complement, less than $5 \%$ immobilization was observed, demonstrating that no immobilizing antibody was present or transferred during the isolation of the treponemes from infected testicles. 


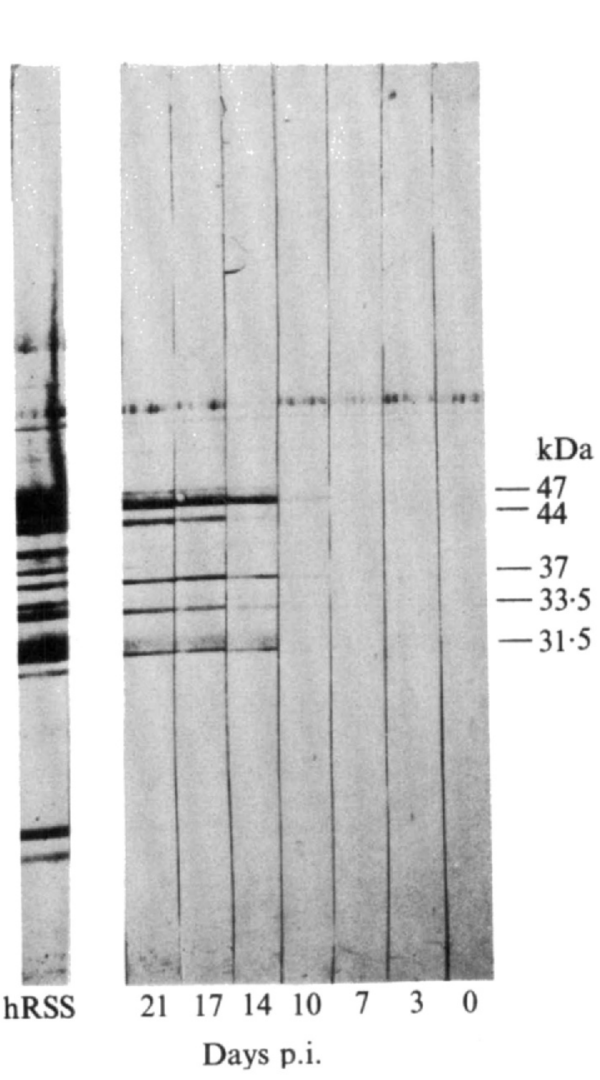

Fig. 3
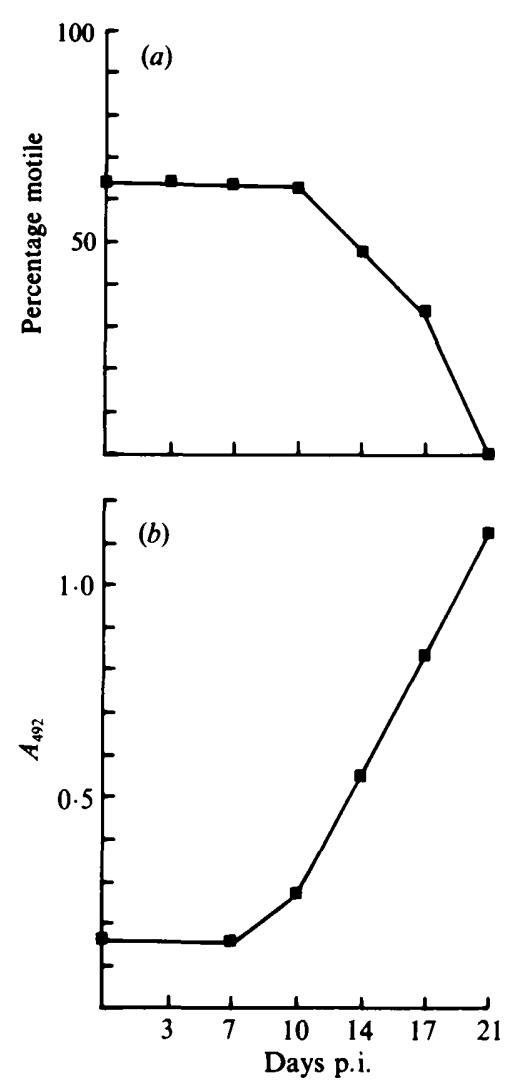

Fig. 4

Fig. 3. Strip immunoblots of whole $T$. pallidum as the antigen reacted with ( $1 / 100$ dilution) rabbit sera taken 0-21 d post intratesticular infection with $5 \times 10^{7} \mathrm{~T}$. pallidum per testis, showing the development and appearance of antibody to specific treponemal polypeptides.

Fig. 4. Complement-dependent TPI activity (a), and indirect ELISA (b) as a measure of the specific anti- $T$. pallidum antibody response detected in the sera collected $0-21 \mathrm{~d}$ p.i. (see Fig. 3 ).

\section{Immunogold electron microscopy}

The surface location of the 44 and $47 \mathrm{kDa}$ polypeptides was inferred by immunogold electron microscopy (Fig. 5). No surface-labelling differences were observed between the Mabs investigated. The intensity of adsorption of the Mabs to the treponemes was considerably less than that recorded under identical conditions for hRSS. The reaction of either Mabs or hRSS with washed but otherwise untreated T. pallidum, as described by Marchitto et al. (1984), resulted in little or no discernible binding above control background levels. In fact strong reactions in suspension were only observed with hRSS-containing mixtures derived from the TPI test. Treponemes derived from the monoclonal antibody-TPI test were not labelled with the gold conjugates. Only the treatment of treponemes with methanol prior to reaction with the Mabs resulted in reproducible and moderately strong binding to the outer surface (Fig. 5). The location of these two antigens is indicated by the close proximity of the electron-dense gold with the permeabilized outer membrane and the observation that Triton-treated unfixed organisms reacted less strongly with anti- $44 \mathrm{kDa}$ or anti- $47 \mathrm{kDa}$ Mabs in this system.

The specificity of the Mabs was confirmed by immunofluorescence: positive reactions were observed only on air-dried acetone-fixed $T$. pallidum cells: Mabs did not react with either $T$. phagedenis or $T$. hyodysenteriae. 

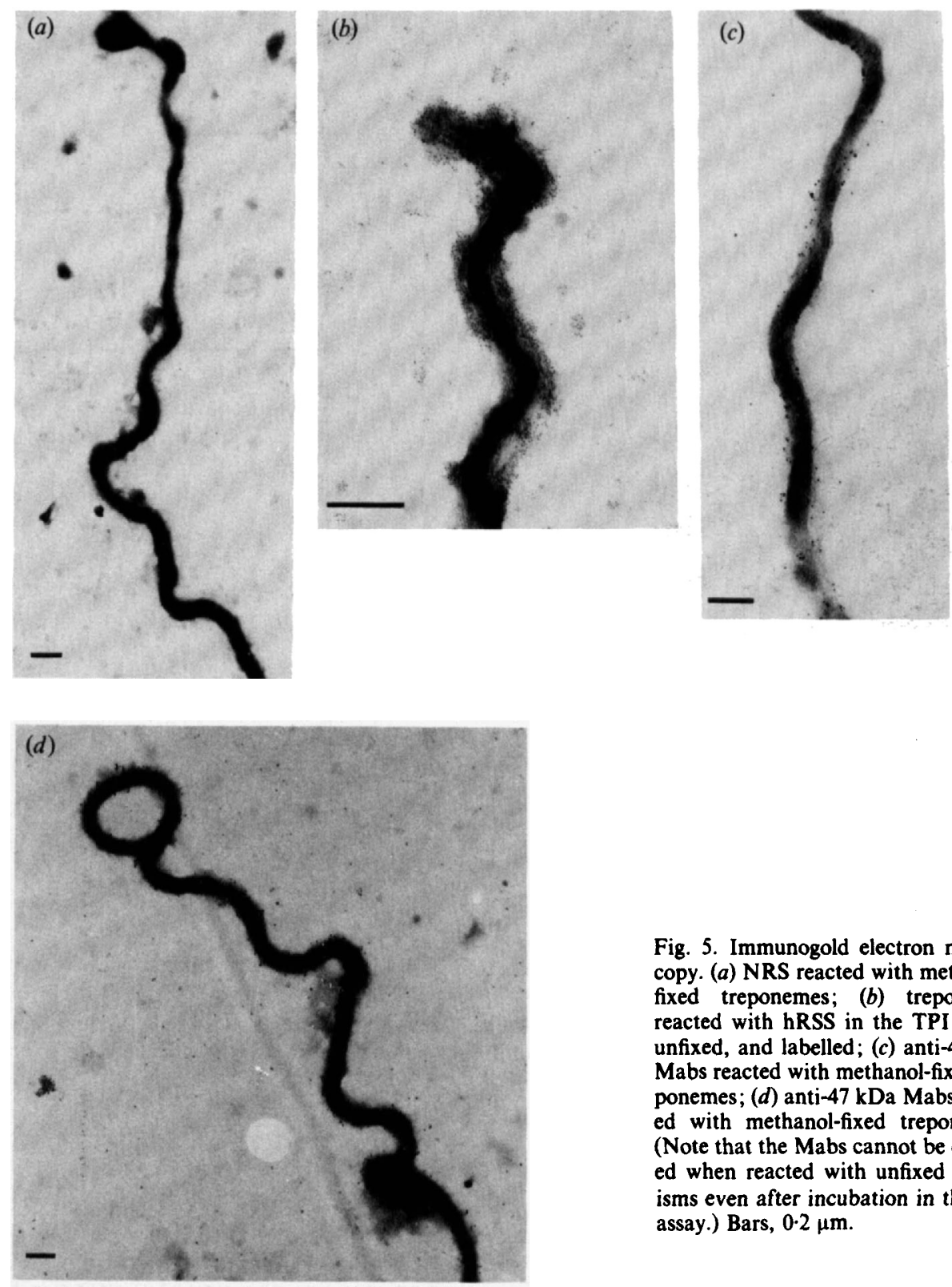

Fig. 5. Immunogold electron microscopy. (a) NRS reacted with methanolfixed treponemes; (b) treponemes reacted with hRSS in the TPI assay, unfixed, and labelled; $(c)$ anti-44 kDa Mabs reacted with methanol-fixed treponemes; $(d)$ anti-47 kDa Mabs reacted with methanol-fixed treponemes. (Note that the Mabs cannot be detected when reacted with unfixed organisms even after incubation in the TPI assay.) Bars, $0.2 \mu \mathrm{m}$.

\section{DISCUSSION}

Other investigators have reported the generation of Mabs with apparently similar specificities to the anti- $44 \mathrm{kDa}$ and anti-47 kDa Mabs described here, as defined either by their reactivity on immunoblots or by radioimmunoprecipitation. It is unclear whether they are directed against the same antigens that we report here. The use of $2 \mathrm{D}$ isoelectrofocusing facilitates a more accurate determination of specificity than can be determined by ID SDS-PAGE. We have observed that accurate assignment of specificity of the Mabs can only be achieved through the use of high-resolution gradient polyacrylamide gels, as on single-concentration SDS-PAGE $(11 \%)$, polypeptides migrating in the same region as the $45 \mathrm{kDa}$ ovalbumin molecular mass marker are poorly separated, and that the use of RIP or immunological detection of precipitates 
is unreliable in this area because of the close proximity of immunoglobulin heavy chain. In order to evaluate the functional capacity of Mabs we needed to know precisely to which antigens they were directed, and without the availability of pure sources of polypeptide we had therefore to select those antibodies that were reactive with native antigen (ELISA, fluorescent antibody) and reactive by Western blotting.

The $47 \mathrm{kDa}$ antigen has been widely reported as an important immunodominant polypeptide in both syphilitic rabbits and man (reviewed by Penn et al., 1986). We have sought to establish which of a variety of polypeptides are involved in evoking a humoral response early in infection so that potential immunogens may be identified and markers for diagnosis elucidated. A rapid response to $47 \mathrm{kDa}$ and $37 \mathrm{kDa}$ antigens was recorded within 7-10 d p.i. in rabbits (Fig. 3). As the infection progressed, the range (Fig. 3) and titre (Fig. $4 b$ ) of the antibody response increased. However, despite the presence of detectable antibody soon after infection no TPI activity was recorded until 14-17 d p.i., coincident with an increase in titre. A similar response was recorded by Wong et al. (1983) with TPI activity apparent after $10 \mathrm{~d}$ p.i. This appearance of immobilizing activity is considered to be associated with the production of antibody to specific polypeptides and coincides with the decline in orchitis and the onset of the disappearance of dermal lesions. By 14-17 d p.i. a number of additional antigens can be detected by Western blotting, including antibody to the $44 \mathrm{kDa}$ antigen. This antigen has recently been implicated in biological activity by Strugnell et al. (1986), who blotted the sera of infected rabbits and compared the appearance of specific antibody with the onset of 'chancre immunity'. We demonstrate here that Mabs to the $44 \mathrm{kDa}$ antigen have specific in vitro TPI activity in all cases. Evidence for the importance specifically of the $44 \mathrm{kDa}$ antigen is provided by the lack of TPI activity associated with any of the three anti-47 kDa Mabs, which were derived from separate parent hybridomas and are of different sub-classes all capable of activating complement. Further, large numbers of treponemes were present in the testes despite a strong antibody response to the $47 \mathrm{kDa}$ antigen at the time of peak orchitis.

The immunization protocol was intentionally selected to enhance the stimulation of antibody to surface-exposed antigens. In the three fusions performed, hybridomas secreting antibody to the $47 \mathrm{kDa}$ antigen predominated, indicating its highly antigenic nature in mice. Additional reports in the literature describe the generation of Mabs against an immunodominant, prominent Coomassie blue-staining polypeptide of approximately $47 \mathrm{kDa}$ which were presumably directed against the same $47 \mathrm{kDa}$ antigen as described here. These Mabs showed differential cross-reactivity with $T$. pertenue and $T$. endemicum (Jones et al., 1984; Marchitto et al., 1984; Thornburg \& Baseman, 1983). To date only Jones et al. (1984) and Marchitto et al. (1986) have described Mabs with TPI activity. One of the Mabs from this research group (11E3) reacts with an antigen of $47 \mathrm{kDa}$. Comparison of the reactivity between $11 \mathrm{E} 3$ (supplied by $\mathrm{M}$. V. Norgard) and our anti-47 kDa Mabs on $T$. pallidum profiles revealed different patterns by immunoblotting: $11 \mathrm{E} 3$ reacted strongly with the $47 \mathrm{kDa}$ polypeptide and cross-reacted weakly with the $44 \mathrm{kDa}$ polypeptide when diluted $1 / 5$ or $1 / 50$, but such cross-reactions were not observed with AD5, AH9 or AD12. These findings suggest that a variety of epitopes may be present on this surface-associated polypeptide. Further evidence for the diversity of antibodybinding sites on this molecule was provided by Lukehart et al. (1985), who reported anti-47 kDa Mabs reactive with an equivalent antigen in $T$. phagedenis, whereas all three Mabs described in this report are specific for $T$. pallidum. However, we have observed that 2 D7 (anti-44 kDa) will react very weakly by immunoblotting with two minor antigens of $T$. phagedenis, of 43 and $45 \mathrm{kDa}$, if reaetions are conducted in the absence of Tween 20 . The reasons for this result are unclear but it may suggest a steric interaction brought about by unusual renaturation of the polypeptides following electrotransfer to NCM.

It is of relevance that none of the polypeptides, apart from the $44 \mathrm{kDa}$ antigen, which stimulate biologically active antisera are detectable in sera taken from rabbits within the first $14 \mathrm{~d}$ of infection, suggesting a central role in treponemal clearance of antibody reactive with the $44 \mathrm{kDa}$ antigen and the ability of $T$. pallidum to effectively mask or avoid normal host surveillance before the appearance of this antibody.

Attempts to localize the $44 \mathrm{kDa}$ antigen on the surface of intact (native) $T$. pallidum were 
unsuccessful despite the observed biological activities, phenomena usually attributable to reactions with bacterial surface components. This suggests that relatively small quantities of the antigen are available for reaction with antibody despite its relative abundance in the bacterium and may account for the prolonged incubation times required in the TPI assay in which some modification of the outer membrane might be required before antibody binds. The inability of the anti-47 kDa Mabs to react in the TPI assay is in agreement with the observations in vivo where large numbers of treponemes remain viable in the testis despite the antibody response to this antigen. The detection of antibody to the $47 \mathrm{kDa}$ antigen on the surface of treponemes immobilized by hyperimmune syphilitic serum (A. Cockayne, unpublished observations) indicates either that this antibody is able to bind to the surface without stimulating immobilization or that 'lethal' binding of antibodies of certain specificities in immune sera may modify the membrane and allow access of antibody of other specificities including anti-47 kDa. Such modification of the membrane might occur early in infection in vivo, leading to opsonization and clearance of the organism allowing an early humoral response to those highly antigenic polypeptides exposed in the damaged organisms. The inability of some intact organisms to bind antibody would partially explain their persistence in infected tissue. This hypothesis is supported by observations made in the in vitro opsonization assay where Mabs to both the $44 \mathrm{kDa}$ and $47 \mathrm{kDa}$ antigens performed equally well (A. Cockayne, unpublished observations). Also, Mabs to the $T$. pallidum $37 \mathrm{kDa}$ axial filament polypeptide have opsonizing activity in this assay (unpublished observations). As the axial filament structure is located beneath the outer membrane any reactivity with this structure must indicate that the outer membrane is in some way damaged, and the promotion of phagocytosis in vitro may be due to the opsonization of a small proportion of damaged organisms present in any population but overlooked in the less sensitive TPI assay.

Through the generation of monoclonal antibodies to two surface-associated polypeptides we have been able to demonstrate in parallel with data obtained from experimentally infected rabbits that antibody to a $44 \mathrm{kDa}$ polypeptide specifically is involved in the possible modulation of syphilis infection. Although such data cannot clarify the retention or persistence of the organism in lesions during infection they do demonstrate that initially the humoral arm of the immune response to relevant antigens is delayed and by 14-17 d p.i. opsonizing and immobilizing antibody can be detected, coincident with the clearance of the majority of $T$. pallidum from the primary site of invasion.

We wish to thank Dr A. Kaminski, of the plant molecular biology laboratory in this department, for her assistance and guidance with the $2 \mathrm{D}$ electrophoresis, $\mathrm{A}$. Wright for her excellent technical help, and $\mathrm{Dr} \mathrm{M}$. E. Hoadley for assistance in the preparation of Mabs. This work was funded in part by the BTG.

\section{REFERENCES}

Alderete, J. F. \& Baseman. J. B. (1980). Surface characterization of virulent Treponema pallidum. Infection and Immunity 30, 814-823.

Alderete, J. F. \& BASEman. J. B. (1981). Analysis of serum IgG against Treponema pallidum protein antigens in experimentally infected rabbits. British Journal of Venereal Diseases 57, 302-308.

BAKer-ZANDER, S. A., HoOK, E. W., Bonin, H. H., HANdSField, H. H. \& LukehaRT, S. A. (1985). Antigens of Treponema pallidum recognised by IgG and IgM antibodies during syphilis in humans. Journal of Infectious Diseases 151, 264-272.

Baseman, J. B. \& Hayes, E. C. (1980). Molecular characterization of receptor binding proteins and immunogens of virulent Treponema pallidum. Journal of Experimental Medicine 151, 573-586.

Bishop, N. H. \& MilleR, J. N. (1976). Humoral immunity in experimental syphilis. II. The relationship of neutralizing factors in immune serum to acquired resistance. Journal of Immunology 117, 197207.
Cockayne, A., Bailey, M. J. \& Penn, C. W. (1987). Analysis of sheath and core structures of the axial filament of Treponema pallidum. Journal of General Microbiology 133, 1397-1407.

Fieldsteel, A. H., Cox, D. L. \& Moeckli, R. A. (1981). Cultivation of virulent Treponema pallidum in tissue culture. Infection and Immunity 32, 908-915.

Fieldsteel, A. H., Cox, D. L. \& Moeckli, R. A. (1982). Further studies on replication of virulent Treponema pallidum in tissue cultures of SfIEp cell. Infection and Immunity 35, 449-455.

Hanff, P. A., Fehniger, T. E., Miller, J. N. \& LOVETT, M. A. (1982). Humoral immune response in human syphilis to polypeptides of Treponema pallidum. Journal of Immunology 129, 1287-1291.

Hanff, P. A., Bishop, N. H., Miller, J. N. \& LovetT, M. A. (1983a). Humoral immune response in experimental syphilis to polypeptides of Treponema pallidum. Journal of Immunology 131, 1973-1977.

Hanff, P. A., Miller, J. N. \& Lovett, M. A. (1983b). 
Molecular characterization of common treponemal antigens. Infection and Immunity 40, 825-828.

Healing, T. D. (1978). A method for the collection of small volumes of whole blood in the field and their preparation for serological studies. Journal of Zoology 185, 273-277.

Jones, S. A., Marchitto, K. S., Miller, J. N. \& NoRGARD, M. V. (1984). Monoclonal antibody with haemagglutination, immobilization and neutralization activities defines an immunodominant, $47,000 \mathrm{~mol}$ wt. surface exposed immunogen of Treponema pallidum (Nichols). Journal of Experimental Medicine 160, 1404-1420.

KoHler, G. \& Milstein, C. (1975). Continuous cultures of fused cells secreting antibody of predetermined specificity. Nature, London 256, 495-497.

LAEMMLI, U. K. (1970). Cleavage of structural proteins during the assembly of the head of bacteriophage T4. Nature, London 227, 680-685.

LUKeHART, S. A., BAKER-ZANDER, S. A. \& GRUBish, E. R., JR (1982). Identification of Treponema pallidum antigens; comparison with non-pathogenic treponemes. Journal of Immunology 129, 833-838.

LUKehart, S. A., TAM, M. R., HoM, J., BakerZANDER, S. A., Holmes, K. K. \& Nowinski, R. C. (1985). Characterization of monoclonal antibodies to Treponema pallidum. Journal of Immunology 134, 585-592.

Lukehart, S. A., Baker-Zander, S. A. \& Sell, S. (1986). Characterization of the humoral response of the rabbit to antigens of Treponema pallidum after experimental infection and therapy. Sexually Transmitted Diseases 13, 9-15.

MARchitto, K. S., Jones, S. A., Schell, R. F., Holmans, P. L. \& Norgard, M. V. (1984). Monoclonal antibody analysis of specific antigenic similarities among pathogenic Treponema pallidum subspecies. Infection and Immunity 45, 660-666.

Marchitto, K. S., Selland-Grossling, C. K. \& NoRGard, M. V. (1986). Molecular specificities of monoclonal antibodies directed against virulent Treponema pallidum. Infection and Immunity 51, 168176.

Moskophidis, M. \& Muller, F. (1984). Molecular analysis of immunoglobulins $M$ and $G$ immune response to protein antigens of Treponema pallidum in human syphilis. Infection and Immunity 43, 127132.

Nelson, R. A. \& MAYer, M. M. (1949). Immobilization of Treponema pallidum in vitro by antibody produced in syphilitic infection. Journal of Experimental Medicine 89, 369-373.

NoRRIS, S. J. (1982). In vitro cultivation of Treponema pallidum. Independent confirmation. Infection and Immunity 36, 437-439.

NoRris, S. J. \& SELl, S. (1984). Antigenic complexity of Treponema pallidum: antigenicity and surface localization of major polypeptides. Journal of Immunology 133, 2686-2692.

OAKLEY, B. R., KIRSCH, D. R. \& MORRIS, N. R. (1980). A simplified ultrasensitive silver stain for detecting proteins in polyacrylamide gels. Analytical Biochemistry 105, 361-363.

O'FARRELl, P. H. (1975). High resolution two-dimensional electrophoresis of proteins. Journal of Biological Chemistry 250, 4007-4021.
Pederson, N. S., Axelsen, N. H. \& Petersen, C. S. (1981). Antigenic analysis of Treponema pallidum: cross reactions between individual antigens of Treponema pallidum and $T$. reiter. Scandinavian Journal of Immunology 13, 143-150.

PENN, C. W. (1981). Avoidance of host defences by Treponema pallidum in situ and on extraction from infected rabbit testes. Journal of General Microbiology 126, 69-75.

PENN, C. W. (1983). The use of the rabbit as a model for syphilis infection. In Experimental Bacterial and Parasitic Infections, pp. 145-151. Edited by G. Keusch \& T. Wadstrom. Amsterdam: Elsevier Biomedical.

PenN, C. W. \& Rhodes, J. G. (1982). Surface associated antigens of Treponema pallidum concealed by an inert outer layer. Immunology 46, 9-16.

Penn, C. W., Cockayne, A. \& Bailey, M. J. (1985). The outer membrane of Treponema pallidum : biological significance and biological properties. Journal of General Microbiology 131, 2349-2357.

Penn, C. W., Bailey, M. J. \& Cockayne, A. (1986). Molecular and immunochemical analysis of Treponema pallidum. FEMS Microbiology Reviews 32, 139148.

Robertson, S. M., Kettman, J. R., Miller, J. N. \& Norgard, M. V. (1982). Murine monoclonal antibodies specific for virulent Treponema pallidum (Nichols). Infection and Immunity 36, 1076-1085.

Strugnell, R. A., Williams, W. F., Drummond, L., Pedersen, J. S., Toh, B. H. \& Faine, S. (1986). Development of increased serum immunoblot reactivity against a 45,000-dalton polypeptide of Treponema pallidum (Nichols) correlates with the establishment of chancre immunity in syphilitic rabbits. Infection and Immunity 51, 957-960.

Thornburg, R. W. \& Baseman, J. B. (1983). Comparison of major protein antigens and protein profiles of Treponema pallidum and Treponema pertenue. Infection and Immunity 42, 623-627.

ThORNBurg, R. W., MORRISON-Plummer, J. \& BASEMAN, J. B. (1985). Monoclonal antibodies to Treponema pallidum: recognition of a major polypeptide antigen. Genitourinary Medicine 61, 1-6.

Towbin, H., Staehelin, T. \& Gordon, J. (1979). Electrophoretic transfer of proteins from polyacrylamide gels to nitrocellulose sheets: procedure and some applications. Proceedings of the National Academy of Sciences of the United States of America 76, 4350-4354.

Van Embden, J. D., Van Der Donk, H. J., Van EiJK, R. V., Van Der Heide, H. G., De Jong, J. A., Van Olderen, M. F., Osterhaus, A. D. \& Schouls, L. M. (1983). Molecular cloning and expression of Treponema pallidum DNA in Escherichia coli K-12. Infection and Immunity 42, 187-196.

Voller, A., Bidwell, D. E. \& Bartlett, A. (1979). ELISA, a Guide with Abstracts of Microplate Applications. Dynatech Publications.

Wong, G. H. W., Steiner, B. \& Graves, S. (1983). Effect of syphilitic rabbit sera taken at different periods after infection on treponemal motility, treponemal attachment to mammalian cells in vitro, and treponemal infection in rabbits. British Journal of Venereal Diseases 59, 220-224. 